\title{
Emergency Management of Metastatic Spinal Cord Compression
}

\author{
Muhammad Muaz Abbasi ${ }^{1, *}$, Sheikh Muhammad Ebad Ali ${ }^{2}$, Badar Saheto ${ }^{2}$, Syed Itaat Hussain Zaidi ${ }^{2}$ \\ ${ }^{1}$ Ziauddin Medical University, Karachi, Pakistan.
}

${ }^{2}$ Department of Orthopedics, Dr. Ruth KM Pfau Civil Hospital, Karachi, Pakistan.

Metastatic Spinal Cord Compression (MSCC) is one of the major forms of oncological emergencies. Other common emergency scenarios seen in cancer patients include Neutropenic Sepsis, Hypercalcemia and Superior Vena Cava Obstruction (SVCO). During this brief discussion of MSCC we will be going over the red flag symptoms a patient may present with common malignancies. We shall go through the points that are associated with and the multidisciplinary management of MSCC.

A patient presenting to the emergency room with symptoms including recent onset back pain [1,2], in the extremes of age (i.e. $<20$ or $>55$ ), with a history of weight loss, pyrexia, night sweats, sensory loss, leg weakness, constant pain at night and at rest and/or complains of urinary retention, fecal incontinence should have MSCC considered in differential diagnosis and appropriate work up should be considered.

MSCC is the commonest neurological complication of cancer. Approximately 5\% of cancer patients have shown development of MSCC and studies have shown the possibility of paralysis if management is deferred by even a few hours [3]. The most commonly involved cancers are of Breast, Prostate, Lung and Hematological origins. The mechanism can be soft tissue infiltration of the spinal canal, compression of the vertebrae or "drop metastasis" in which metastasis goes into the Cerebro Spinal Fluid (CSF) space.

In Emergency Room (ER), generally, a patient presenting with lesions above first lumber vertebra (L1) will be showing Upper Motor Neuron pathological signs and lesions below L1 will show clinical features of cauda equina syndrome. Sixty percent of patients will have complaints of pain. If the patient is a known case of malignancy, the clinical oncology team should be taken on board. If the patient history is unknown and is presenting with above mentioned red flags, an urgent Magnetic Resonance Imaging (MRI) of the whole spine should be ordered and clinical oncology team should be brought on board.

In a patient with suspected MSCC, $16 \mathrm{mg}$ dexamethasone with Proton Pump Inhibitor cover should be given immediately and

*Address correspondence to this author at the Ziauddin Medical University, Karachi, Pakistan.

Email: muhammad7561@zu.edu.pk an urgent MRI spine done within 24 hours. If MRI comes back positive for MSCC, decision should be made to involve multidisciplinary team starting with an expert opinion from the neuro-surgical team (MDT). The team goes through the full history and clinical findings of the case. The duration of neurological deficit is an important factor which is being considered before making a conclusive recommendation. Ideally, a site specific MSCC MDT Tumor Board is required as a mandatory requirement before commencing the first modality of treatment [4]. First and foremost an expert spinal neuro-surgeon or spinal orthopedic surgeon is being taken. A final recommendation is being made after making emergency evaluations by the multi-disciplinary team including emergency medical services, neurosurgery, radiation and medical oncology teams.

The ideal management for MSCC concluded from multiple studies is postulated as; surgery as the initial treatment with radiotherapy as follow-up. Timely surgery has allowed more patients to remain ambulatory for the remaining period of their lives and has also reduced the need for opioid and corticosteroid pain management [5].

If the patient has multiple spinal areas affected, their performance status is poor or prognosis is less than 3 months palliative radiotherapy can be considered for betterment of symptoms. The side effects of radiotherapy can potentially include a flare in the pain the patient is experiencing, nausea, sickness, and diarrhea. It should be noted that $57 \%$ of patients who are given radiotherapy within 24 hours regain motor function [4]. If motor function is lost for greater than 48 hours, reversal of neurological deficit becomes quite unlikely.

Surgery carries $29 \%$ risk of complications. Infections and pulmonary complications were the most common. A widely cited risk for surgical wound complication is previous exposure to radiation. As such, complication rates were significantly influenced by the burden of systemic disease and neoadjuvant therapies. Radiation therapy, while recognized to be the safer alternative, is also not without risks. The post-radiation clinical course in one study included a $10 \%$ incidence of adverse events, including cardiogenic shock and sepsis [6].

The pitfalls of surgery and radiation therapy should also be 
kept in mind. A 29\% risk of complications (infectious and pulmonary more commonly) has been associated with Surgery; while radiotherapy although recognized to be a safer alternative has shown a $10 \%$ incidence of acute and or chronic side effects. Surgical complication rates are significantly influenced by prior cytotoxic therapies and the burden of cancer elsewhere in the body. Surgical wound complications have been widely associated with previous radiation exposure [6].

\section{AUTHORS' CONTRIBUTION}

All authors contributed equally.

\section{CONFLICT OF INTEREST}

Declared none.

\section{ACKNOWLEDGEMENTS}

Declared none.

\section{REFERENCES}

[1] Lewis MA, Hendrickson AW, Moynihan TJ. Oncologic emergencies: Pathophysiology, presentation, diagnosis, and treatment. CA Cancer J Clin 2011; 61(5): 287-314. DOI:
$10.3322 /$ caac. 20124

[2] Furlan JC, Sakakibara BM, Miller WC, Krassioukov AV. Global incidence and prevalence of traumatic spinal cord injury. Can J Neurol Sci 2013; 40(4): 456-64. DOI: $10.1017 / \mathrm{S} 0317167100014530$

[3] Khan UA, Shanholtz CB, McCurdy MT. Oncologic mechanical emergencies. Emerg Med Clin North Am 2014; 32(3): 495-508. DOI: 10.1016/j.emc.2014.04.001

[4] Asghar AH, Abbasi AN, Rizvi. City tumour board Karachi: An innovative step in multidisciplinary consensus meeting and its two years audit. J Pak Med Assoc 2013; 63(12): 1534-5.

[5] Patchell RA, Tibbs PA, Regine WF, et al. Direct decompressive surgical resection in the treatment of spinal cord compression caused by metastatic cancer: A randomised trial. Lancet 2005; 366(9486): 643-8. 10.1016/S0140-6736(05)66954-1

[6] Kim JM, Losina E, Bono CM, et al. Clinical outcome of metastatic spinal cord compression treated with surgical excision \pm radiation versus radiation therapy alone: A systematic review of literature. Spine (Phila Pa 1976) 2012; 37(1): 78-84. DOI: 10.1097/BRS.0b013e318223b9b6 